\section{(C) OPEN ACCESS}

\title{
Changes in neuromuscular structure and functions of human colon during ageing are region-dependent
}

\author{
John Broad, ${ }^{1}$ Victor W S Kung, ${ }^{1}$ Alexandra Palmer, ${ }^{1}$ Shezan Elahi, ${ }_{1}^{1}$ Azadeh Karami, ${ }^{2}$ \\ Taher Darreh-Shorii, ${ }^{2}$ Shafi Ahmed, ${ }^{3,4}$ Mohamed Adhnan Thaha, ${ }^{1,3,4}$ Rebecca Carroll, ${ }^{1}$ \\ Joanne Chin-Aleong, ${ }^{1}$ Joanne E Martin, ${ }^{1}$ M Jill Saffrey, ${ }_{1}^{5}$ Charles H Knowles, ${ }^{1,3,4}$ \\ Gareth John Sanger ${ }^{\bullet}$
}

\begin{abstract}
- Additional material is published online only. To view please visit the journal online (http://dx.doi.org/10.1136/ gutjnl-2018-316279).
\end{abstract}

${ }^{1}$ Blizard Institute, Barts and The London School of Medicine and Dentistry, Queen Mary University of London, London, UK

${ }^{2}$ Department of Neurobiology, Care Sciences and Society, Karolinska Institutet, NEO, Stockholm, Sweden

${ }^{3}$ Department of Surgery, Barts Health NHS Trust, The Royal London Hospital, London, UK ${ }^{4}$ Department of Pathology, Barts Health NHS Trust, The Royal London Hospital, London, UK 5School of Life, Health and Chemical Sciences, Open University, Milton Keynes, UK

\section{Correspondence to}

Professor Gareth John Sanger, Blizard Institute, Barts and The London School of Medicine and Dentistry, Queen Mary University of London, London $\mathrm{E} 1$ 4NS, UK; g.sanger@qmul.ac.uk

JB and VWSK contributed equally.

Received 16 February 2018 Revised 17 August 2018 Accepted 20 August 2018 Published Online First 18 September 2018

Check for updates

(C) Author(s) (or their employer(s)) 2019. Re-use permitted under CC BY-NC. No commercial re-use. See rights and permissions. Published by BMJ.

To cite: Broad J, Kung VWS, Palmer A, et al. Gut

2019:68:1210-1223.

\section{ABSTRACT}

Objective To determine if human colonic

neuromuscular functions decline with increasing age.

Design Looking for non-specific changes in neuromuscular function, a standard burst of electrical field stimulation (EFS) was used to evoke neuronally mediated (cholinergic/nitrergic) contractions/relaxations in ex vivomuscle strips of human ascending and descending colon, aged 35-91 years (macroscopically normal tissue; 239 patients undergoing cancer resection). Then, to understand mechanisms of change, numbers and phenotype of myenteric neurons (30306 neurons stained with different markers), densities of intramuscular nerve fibres (51 patients in total) and pathways involved in functional changes were systematically investigated (by immunohistochemistry and use of pharmacological tools) in elderly ( $\geq 70$ years) and adult (35-60 years) groups.

Results With increasing age, EFS was more likely to evoke muscle relaxation in ascending colon instead of contraction (linear regression: $n=109$, slope $0.49 \% \pm 0.21 \% /$ year, $95 \% \mathrm{Cl}$ ), generally uninfluenced by comorbidity or use of medications. Similar changes were absent in descending colon. In the elderly, overall numbers of myenteric and neuronal nitric oxide synthaseimmunoreactive neurons and intramuscular nerve densities were unchanged in ascending and descending colon, compared with adults. In elderly ascending, not descending, colon numbers of cell bodies exhibiting choline acetyltransferase immunoreactivity increased compared with adults ( $5.0 \pm 0.6$ vs $2.4 \pm 0.3$ neurons/ $\mathrm{mm}$ myenteric plexus, $\mathrm{p}=0.04)$. Cholinergically mediated contractions were smaller in elderly ascending colon compared with adults $(2.1 \pm 0.4$ and $4.1 \pm 1.1 \mathrm{~g}$-tension $/ \mathrm{g}$ tissue during EFS; $n=25 / 14 ; p=0.04)$; there were no changes in nitrergic function or in ability of the muscle to contract/relax. Similar changes were absent in descending colon.

Conclusion In ascending not descending colon, ageing impairs cholinergic function.

\section{INTRODUCTION}

There is evidence that human GI functions change in the elderly ( $>65-70$ years), ${ }^{1}$ contributing to the development of constipation with associated pain, loss of dignity, reduced quality of life, faecal impaction and incontinence. ${ }^{12}$ Approximately

\section{Significance of this study}

What is already known on this subject?

- Studies in ageing rodents suggest loss of myenteric neurons and a decline in cholinergic function of the colon. However, not all studies agree and uncertainty exists in terms of how these findings translate to humans.

- Studies using human colon have generally used small numbers of tissues with variable or undefined clinical history and heterogeneous techniques, generating inconsistent data.

- Nevertheless, a decline in neuromuscular functions has been suggested to contribute to the mechanisms underlying the increased incidence of constipation among the elderly.

What are the new findings?

- In a large functional study (ascending/ descending colon from, respectively, 109 and 130 patients), increasing age increased the likelihood that electrical nerve stimulation caused muscle relaxation in ascending colon, instead of contraction, but no age-related changes were observed in descending colon.

- The functional changes with increasing age were not explained by loss of neurons within the myenteric plexus, reduced density of intramuscular axon bundles or changes in numbers of nitrergic neurons, but were associated with an increase in choline acetyltransferase (ChAT) immuno-positive myenteric nerve cell bodies in ascending, not descending colon.

- Functional changes with increasing age were explained by a decline in cholinergic function in ascending but not in descending colon (allowing an unchanged nitrergic function to exert greater inhibitory influence on cholinergic activity).

- There were no regional or age-related differences in the ability of the smooth muscle to contract or relax.

$30 \%-40 \%$ of people aged 65 years or older self-report constipation. ${ }^{3}$ However, other factors are important, including changes in diet, fluid intake, exercise, bowel disorders (eg, diverticulitis or 
How might it impact on clinical practice in the foreseeable future?

- The new findings indicate that absolute or selective neuronal loss is not likely in itself to be an important aetiological factor in lower GI symptoms associated with ageing.

- The detection of age-dependent changes in ascending but not descending colon (decreased cholinergic function and increased myenteric somal ChAT immunostaining) indicates that greater attention needs to be paid to region-dependent differences in how the human colon ages and in particular, the changes which occur within the cholinergic innervation.

bowel cancer) and use of medications that reduce GI motility (eg, opioid-based analgesics, tricyclic antidepressants, calcium-channel antagonists ${ }^{24}$ ).

In rodents, declining colonic neuromuscular functions are reported during increasing age; some ${ }^{56}$ (not all ${ }^{7}$ ) report reduced numbers of myenteric cholinergic neurons and glial cells, reduced mucosal secretory capacity and slower intestinal transit. However, caution is required when translating such data to humans. Rodents have high metabolic rates, relatively short life spans $^{8}$ and GI physiology distinct from primates, with functional disparities reflected by differences in anatomy, neuronal functions, receptor pharmacology and molecular structures. ${ }^{9}$ Further complications are caused by genetic variation between different strains of laboratory rodents, ${ }^{10}$ including differences in loss of myenteric nitrergic neurons during advanced age. ${ }^{11}$ Alternative use of baboons ${ }^{12}$ does not entirely remove translational uncertainty (the colon has adapted to fruit and vegetable diets ${ }^{13}$ ) and regardless, these animals are not suitable for routine research. Functional studies in humans have generated contradictory findings, perhaps due to small sample sizes with unclear medical history and heterogeneous experimental approaches. ${ }^{14-16}$

This study aimed to determine if age-associated changes in neuromuscular functions can be identified using ex vivo preparations of human ascending and descending colon and then determine mechanisms of change by multiple, systematic anatomical and pharmacological approaches.

\section{MATERIALS AND METHODS}

\section{Patients and tissues}

After ethical approval (REC 10/H0703/71), written informed consent was obtained for use of macroscopically normal ascending and descending/sigmoid (referred to hereon as descending) colon $(5-10 \mathrm{~cm}$ from tumour) from patients undergoing elective surgery for non-obstructing bowel cancer. Patient records were examined for ongoing medication and comorbidity; clinical investigations into bowel functions were not conducted. No patient had previous chemoradiotherapy or diagnosis of inflammatory bowel disease. Tissue was immersed into preoxygenated Krebs solution 60-120 min after surgery. When investigating mechanisms, two discontinuous age groups were studied, either side of the overall median age of patients examined: adult (35-60 years) and elderly ( $\geq 70$ years).

\section{Anatomical studies}

Histopathology

Full thickness tissues, orientated to demonstrate mucosal, submucosal, muscularis and serosal layers, $\sim 1 \times 1 \mathrm{~cm}$, were fixed and embedded in paraffin blocks prior to cutting into multiple $4 \mu \mathrm{m}$ thick sections. Sections were stained with H\&E for routine histopathological assessment. Significant inflammation was excluded by observation of crypt architecture, distortion and atrophy, lamina propria cellularity, basal plasmacytosis, active inflammation, granulomata, mucin depletion, crypt abscesses, cryptitis and ulceration. ${ }^{17}$

\section{Myenteric neuronal quantitation}

Neurons were immunostained using anti-human neuronal protein C/D (anti-HuC/D; pan-neuronal antigen for cytoplasmic RNA-binding proteins, labelling cell nucleus and perikaryon ${ }^{18}$ ), anti-choline acetyltransferase (anti-ChAT) and anti-neuronal nitric oxide synthase (anti-nNOS). For each, a median of seven sections were examined for each patient (so not less than $10 \mathrm{~mm}$ of stained myenteric plexus could be studied, usually more). Each section was cut from the same block (minimum $16 \mu \mathrm{m}$ separation). Following antigen retrieval and visualisation, cell nuclei were counterstained with hematoxylin. Positive and negative controls were performed in colon (anti-Hu/C/D, antinNOS) and spinal cord (anti-ChAT), with or without primary antibodies. Stained slides were scanned and digitally visualised.

For neuronal quantitation, a line was drawn along the myenteric plexus (freehand draw function in viewing software). For ganglion counts, sections stained with anti-HuC/D were viewed at $\sim 40 \times$ magnification. To quantify cell bodies within each ganglion, sections stained with anti-HuC/D were viewed at $60 \times-80 \times$ magnification. Subclasses of myenteric cell bodies were counted separately after staining with anti-ChAT and antinNOS. Counting of ganglia and cell bodies ${ }^{19}$ and other assessments of staining were performed by two independent observers 'blinded' to patient identity/age (online supplementary file 1).

\section{Densitometric analysis of intramuscular nerve fibre bundles}

Sections were labelled using anti-protein gene product 9.5 (anti-PGP9.5) (online supplementary file 1) to examine changes in axons/nerve fibre bundles in the muscle. Stained slides were scanned, digitally visualised and two non-adjacent areas from each of three different regions investigated per section: circular

Table 1 Patients and tissues used

\begin{tabular}{|c|c|c|c|c|c|c|c|}
\hline \multirow[b]{2}{*}{ Region of colon } & \multicolumn{3}{|c|}{ All tissues studied } & \multirow{2}{*}{$\begin{array}{l}\text { Tissues used for } \\
\text { functional studies } \\
\text { n (strips) }\end{array}$} & \multicolumn{3}{|c|}{ Tissues used for H\&E staining } \\
\hline & $\mathbf{n}$ & Age (years) & $\begin{array}{l}\text { Gender } \\
\text { (male:female) }\end{array}$ & & Age (years) & Evidence of inflammation (ages) & $\mathrm{n}$ \\
\hline Ascending & 113 & $69 \pm 1(35-91)$ & $0.7: 1$ & $109(1020)$ & $67 \pm 3(40-91)$ & $4(60,73,78,78$ years $)$ & 30 \\
\hline Descending/sigmoid & 132 & $65 \pm 1(35-91)$ & 1.4: 1 & $130(1276)$ & $66 \pm 3(35-91)$ & 2 (60, 78 years) & 28 \\
\hline
\end{tabular}

$\mathrm{n}$, number of patients (for functional studies, numbers of muscle strips used are given in parenthesis). The ages of the patients are given as mean \pm SEM with ranges in parenthesis. For functional studies, tissues were used after overnight storage in fresh Krebs solution at $4^{\circ} \mathrm{C}$ (188 tissues), 44 on the day of surgery and 7 on the day of surgery and after storage. 
A Ascending colon

Adult

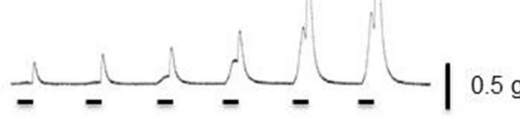

Elderly

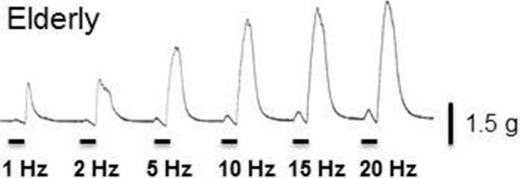

Descending colon

Adult

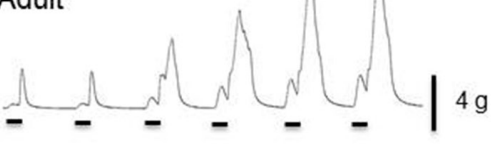

Elderly

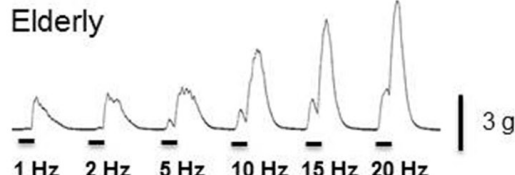

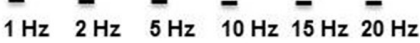

B

Adult Ascending colon

Adult Descending colon
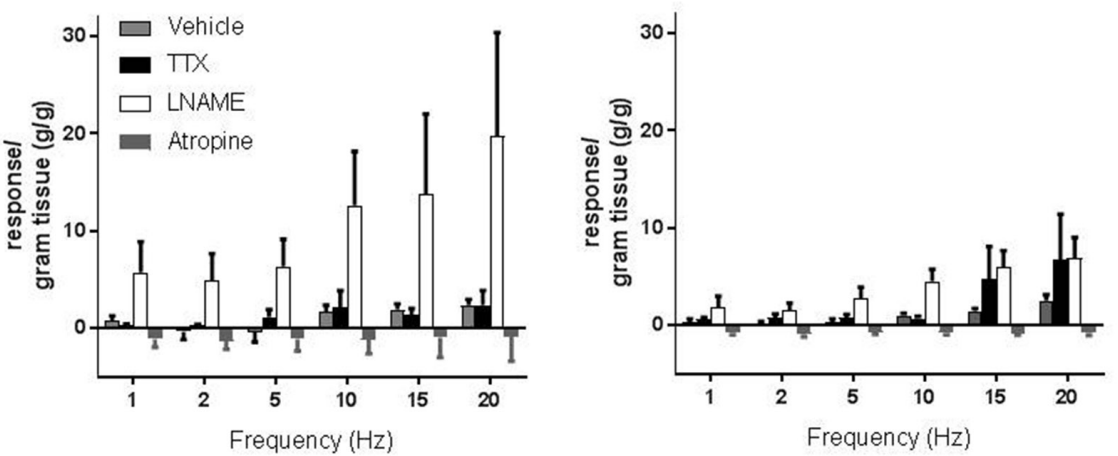

C

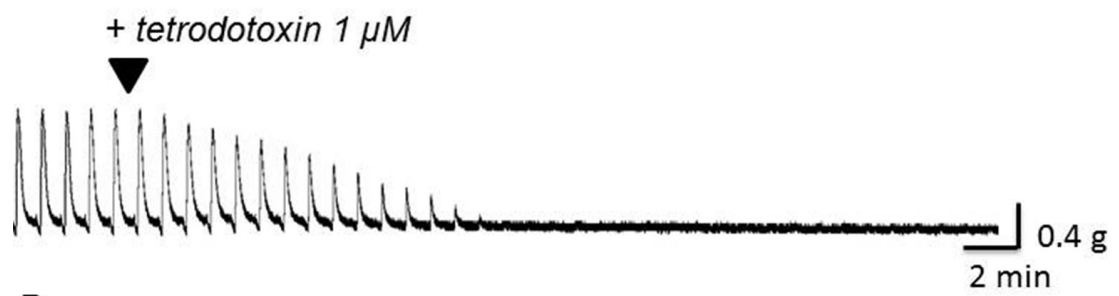

D
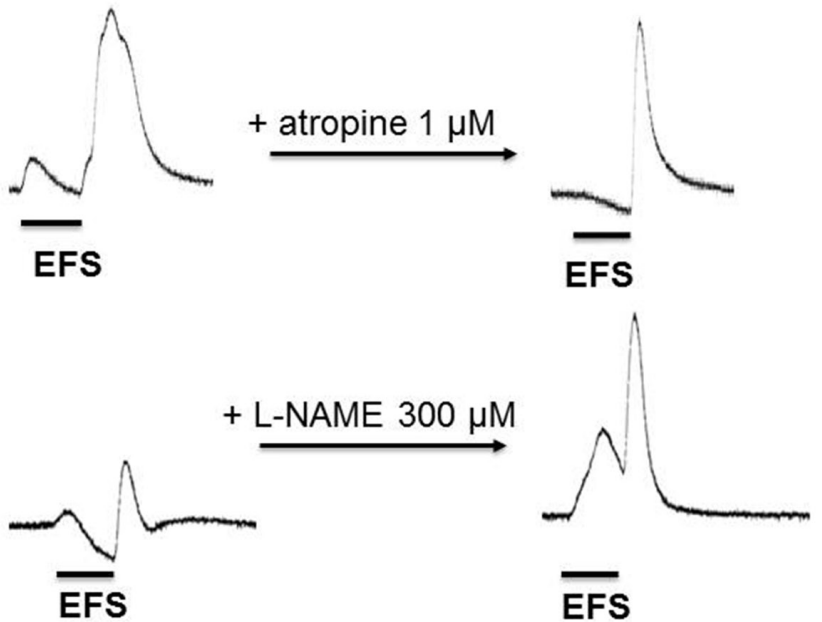

Figure 1 The effects of electrical field stimulation (EFS) in circular muscle of ascending and descending colon from adult (35 to 60 years) and elderly ( $\geq 70$ years) patients. Panel A shows representative trace examples illustrating responses during and after termination of EFS over a range of frequencies of stimulation. EFS was applied at $1-20 \mathrm{~Hz}$ and at $50 \mathrm{~V}$ for $10 \mathrm{~s}$ every $1 \mathrm{~min}$. Using tissues from the adult group, panel B shows the overall contraction force (mean \pm SEM g tension/g wet weight of tissue) generated during EFS in both regions of colon for each frequency of stimulation in the presence of vehicle, tetrodotoxin (TTX) $1 \mu \mathrm{M}$, atropine $1 \mu \mathrm{M}$ or L-NAME ( $\mathrm{N}_{-}$-nitro-L-arginine methyl ester hydrochloride) $300 \mu \mathrm{M}$ ( $\mathrm{n}=5$ each). Panels $\mathrm{C}$ and $\mathrm{D}$ show responses to $\mathrm{EFS}$ at $5 \mathrm{~Hz}, 50 \mathrm{~V}$ for $10 \mathrm{~s}$, repeated every $1 \mathrm{~min}$. The individual trace in panel C illustrates the ability of TTX $1 \mu \mathrm{M}$ to inhibit responses evoked by repeated EFS. In panel D, the effects of single bursts of EFS are shown before and after treatment with atropine $1 \mu \mathrm{M}$ or L-NAME $300 \mu \mathrm{M}$, in two muscle strips cut from the same tissue (male, 74, descending colon). The 10s period of EFS is indicated by the horizontal bars (note the expanded time scale relative to panel C). Atropine inhibited contractions during EFS and decreased after-contractions. L-NAME inhibited relaxations during EFS and facilitated contraction amplitudes. 
Table 2 Pharmacology of responses to EFS in circular muscle from human adult ascending and descending colon

\begin{tabular}{|c|c|c|c|c|c|}
\hline \multirow[b]{2}{*}{ Drug } & \multirow[b]{2}{*}{ Response } & \multicolumn{2}{|c|}{ Adult ascending } & \multicolumn{2}{|c|}{ Adult descending } \\
\hline & & $\begin{array}{l}\text { During EFS } \\
\text { (g/g tension) }\end{array}$ & $\begin{array}{l}\text { After EFS } \\
\text { (g/g tension) }\end{array}$ & $\begin{array}{l}\text { During EFS } \\
\text { (g/g tension) }\end{array}$ & $\begin{array}{l}\text { After EFS } \\
\text { (g/g tension) }\end{array}$ \\
\hline $\begin{array}{l}\text { Atropine } \\
1 \mu \mathrm{M}\end{array}$ & $\begin{array}{l}\text { Contraction prevented during EFS, revealing or enhancing } \\
\text { relaxation; contractions after EFS attenuated }\end{array}$ & $-2.6 \pm 1.0(6)$ & $-1.8 \pm 0.8(4)$ & $-1.7 \pm 0.6(8)$ & $-1.8 \pm 0.5(8)$ \\
\hline $\begin{array}{l}\text { Atropine plus } \mathrm{NK}_{1-3} \\
\text { antagonists }\end{array}$ & $\begin{array}{l}\text { As above but with consistent inhibition of contractions } \\
\text { after EFS }\end{array}$ & $-4.4 \pm 2.1(5)$ & $-1.5 \pm 0.5(3)$ & $-0.7 \pm 0.4(4)$ & $-4.1 \pm 1.9(3)$ \\
\hline $\begin{array}{l}\text { L-NAME } \\
300 \mu \mathrm{M}\end{array}$ & $\begin{array}{l}\text { Contraction during EFS increased in ascending colon only; } \\
\text { no consistent effect on contractions after EFS }\end{array}$ & $3.2 \pm 1.1(14)$ & $-0.2 \pm 1.2(7)$ & $0.8 \pm 0.5(16)$ & $0.8 \pm 0.7(14)$ \\
\hline $\begin{array}{l}\text { MRS2500 } \\
1 \mu \mathrm{M}\end{array}$ & No consistent change during and after EFS & $0.8 \pm 0.5(5)$ & $0.1 \pm 0.3(3)$ & $0.3 \pm 0.1(4)$ & $-2.3 \pm 1.0(3)$ \\
\hline
\end{tabular}

EFS was applied at $5 \mathrm{~Hz}, 50 \mathrm{~V}$ for $10 \mathrm{~s}$, repeated every $1 \mathrm{~min}$. The effects of treatment with atropine, NK ${ }_{1,2,3}$ receptor antagonists (L732138 $1 \mu \mathrm{M}$, GR $1598970.1 \mu \mathrm{M}$ and SB$2353750.1 \mu \mathrm{M}$, applied together and in the presence of atropine), L-NAME and MRS2500 are shown for the responses during and after EFS. Data are given as the decrease or increase in mean \pm SEM of the overall muscle tension during each phase of EFS, expressed as $\mathrm{g}$ tension/g wet weight of tissue. The $\mathrm{n}$ values (in parenthesis) refer to numbers of patients; since after-contractions were not consistently observed in tissues from all patients, these were sometimes smaller.

EFS, electrical field stimulation; L-NAME, $\mathrm{N}_{\omega}$-nitro-L-arginine methyl ester hydrochloride.

muscle near myenteric plexus, circular muscle close to the mucosa (deep circular muscle) and longitudinal muscle.

\section{Cholinergic enzyme assays}

ChAT, acetylcholinesterase (AChE) and butyrylcholinesterase (BChE) expression and activity in colon muscle were measured as previously described (online supplementary file 2 ).

\section{Functional studies}

Detailed methods have been described previously. ${ }^{2021}$ In brief, after removing the mucosa, strips were cut parallel to the circular muscle ( $~ 5 \mathrm{~mm}$ wide, $10-15 \mathrm{~mm}$ long; 3-31 from each patient) and mounted in warmed tissue baths containing Krebs solution (mmol/L: $\mathrm{NaCl} 121.5, \mathrm{CaCl}_{2} 2.5, \mathrm{KH}_{2} \mathrm{PO}_{4} 1.2, \mathrm{KCl}$ 4.7, $\mathrm{MgSO}_{4}$ 1.2, $\mathrm{NaHCO}_{3} 25$, glucose 5.6, equilibrated with $5 \% \mathrm{CO}_{2} / 95 \% \mathrm{O}_{2}$ ) for measuring isometric muscle tension. After 1-hour recovery, electrical field stimulation (EFS) was applied and consistent responses obtained.

Responses to EFS were analysed qualitatively by counting numbers of tissues relaxing or contracting. Quantitative measurements were of changes in tension/gram (g) wet weight of tissue; contractions were assigned positive values and relaxations negative values (if relaxation followed contraction, assignment was to the movement of greatest magnitude). Drug-induced changes were differences between the mean of three responses before and $30 \mathrm{~min}$ after drug application. In determining the effects of L-NAME ( $\mathrm{N}_{\omega}$-nitro-L-arginine methyl ester hydrochloride) and atropine (inhibiting, respectively, nitrergic and cholinergic functions in human colon ${ }^{20}$ ), one strip/patient was selected from multiple strips/patient exposed to these drugs for a number of different studies (computer random number generation). Similarly, when determining the influence of age on these responses, strips were randomly selected to match the proportions of phenotype (contraction/relaxation in response to EFS) observed in each region of colon. Non-cumulative concentration- response curves for carbachol (muscarinic $\mathrm{M}_{1}-\mathrm{M}_{5}$ receptor agonist) and sodium nitroprusside (SNP; nitric oxide (NO) donor) were established by applying single concentrations for 15 min or until maximum effect was observed (online supplementary file 3 shows carbachol concentration-response curves).

Drugs were freshly prepared prior to use. Carbachol, atropine, L-NAME , SNP and DEA-NO (diethylamine NONOate; diethylammonium (Z)-1-(N,N-diethylamino)diazen-1-ium1,2-diolate; Sigma, UK), MRS2500 (P2Y receptor antagonist in human colon $^{22}$ ) and tetrodotoxin (TTX; Tocris, UK) were dissolved in distilled water. The L-type calcium channel stabiliser (S)-(-)-Bay K8644 was dissolved in dimethyl sulfoxide (DMSO) (Sigma) to $10 \mathrm{mM}$. A cocktail of neurokinin $(\mathrm{NK})_{1}, \mathrm{NK}_{2}$ and $\mathrm{NK}_{3}$ receptor antagonists was prepared by dissolving L732138 (Tocris) in DMSO, GR159897 (Tocris) and SB235375 (GSK) in ethanol, each to $10 \mathrm{mM}$, for use at, respectively, $1 \mu \mathrm{M}, 0.1 \mu \mathrm{M}$ and $0.1 \mu \mathrm{M}$ bath concentrations, inhibiting tachykinergic functions in human colon. ${ }^{20}$

\section{Statistical analysis}

To test whether patient characteristics affected responses to EFS, measured initially when surveying the effects of age, contingency analyses ( $\chi^{2}$ or Fisher's exact test) were applied as a screening test to two groups (higher or lower than the mean percentage strip relaxation of adult ascending colon), with a conservative level of statistical significance used $(p \leq 0.01)$ to allow for multiple comparisons. On the basis that only one of the 130 covariates evaluated appeared to confound results, multivariable analyses were not performed.

In mechanism-based functional experiments, $\mathrm{EC}_{50}$ and $\mathrm{E}_{\max }$ values were obtained from three-parameter agonist-response curves using GraphPad Prism 7.02. Data are expressed as means \pm SEM. The $n$ values represent number of patients. Differences between means were determined using analyses of variance (ANOVAs) with Sidak's multiple comparisons test for unpaired observations. $P$ value $<0.05$ represented statistical significance.

For anatomical studies, numbers of cell bodies were expressed per millimetre of myenteric plexus. Inter-rater differences (95\% CI) were analysed using one-sample Student's t-tests and proportional biases investigated using Bland-Altman plots (online supplementary file 1). For comparisons, normality testing (D'Agostino \& Pearson) was performed and neurons/ mm length analysed for differences in means using ANOVAs with Sidak's multiple comparisons test (11/12 variables were normally distributed). P value $<0.05$ represented statistical significance.

\section{RESULTS}

\section{Patients}

Two hundred and forty-five patients (122 women; mean age 66 (range 35-91) years) consented to provide fresh surgical colon (table 1). On H\&E staining, only a minority of adult and elderly patients showed low-grade inflammation limited to the mucosa. 
A

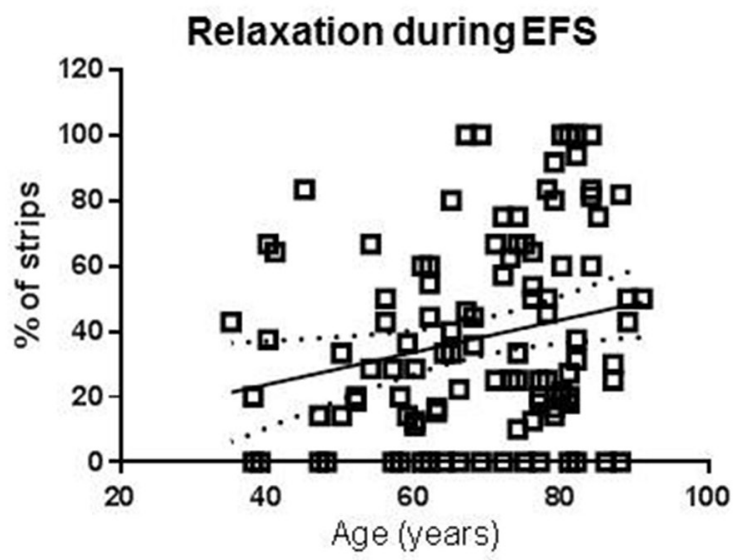

C

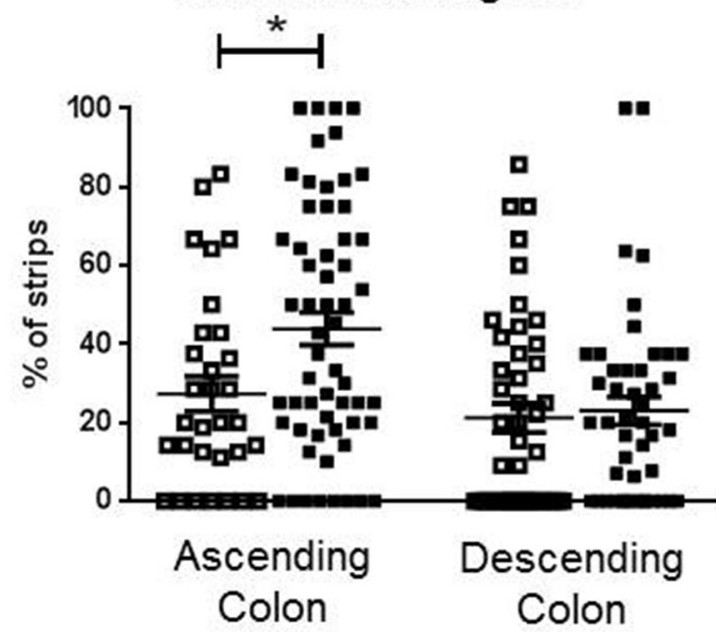

B

Descending Colon

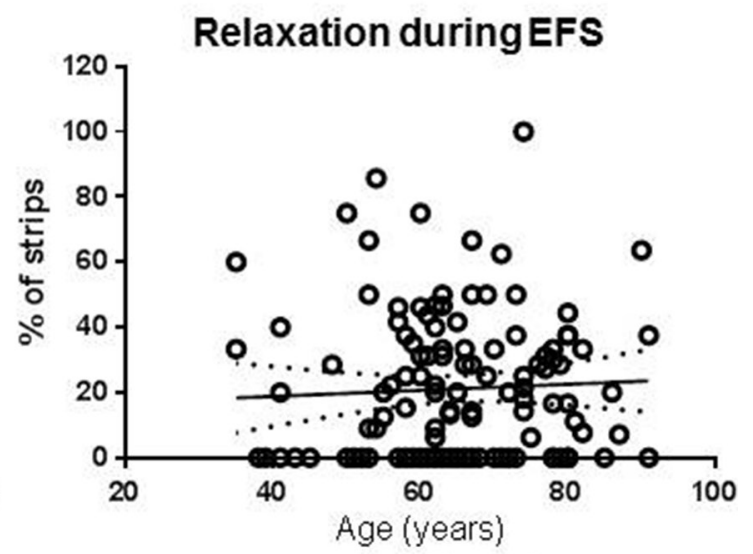

Contraction after EFS

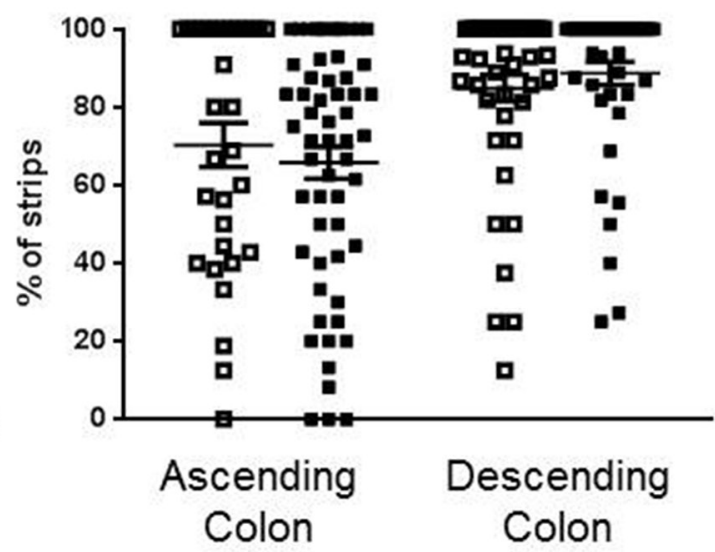

Figure 2 Age-dependent changes in phenotype of response to electrical field stimulation (EFS) in human ascending but not descending colon. For each patient $(n=239)$, a mean of 10 strips (range 3-31) were examined and the number which relaxed or contracted during EFS expressed as the percentage of total tested for that patient. Panel A shows the percent values for relaxation during EFS in ascending colon from all patients. The linear regression line ( $95 \%$ confidence bands as dotted lines) demonstrates an increased likelihood of relaxation as age increases (slope $=0.49 \% \pm 0.21 \% /$ year, $\mathrm{n}=109$ ). Panel $\mathrm{B}$ shows no age-related changes in the percentage values for relaxation during EFS in descending colon (all patients: slope $=0.09 \% \pm 0.17 \% / y e a r, n=130)$. Panel $C$ shows the overall percentage of strips relaxing during EFS for each of the tissues studied and the percentage that contract after EFS, placed in the adult ( $35-60$ years old; $\square$ ) and elderly ( $\geq 70$ years old; $\square$ ) age groups. For ascending colon, $n=31$ and 58 and for descending colon, $n=45$ and 46 . The data are given as means ( \pm SEM). These were analysed using analysis of variance with Sidak's multiple comparison tests; * $p<0.05$. For comparison between adult ascending and descending colon contraction after EFS, $p=0.06$, all other comparisons between adult groups, and adult and elderly groups were not statistically significant ( $p>0.70$ ).

\section{Age-related changes in overall function}

Before examining mechanisms of change we looked for existence of any non-specific change in neuromuscular function, using a standard burst of EFS to evoke neuronally mediated contractions/relaxations in muscle strips from large numbers of human ascending and descending colon over a wide age range (35-91 years).

Preliminary experiments

To determine the optimal frequency to study, frequency-response curves were constructed using adult $(n=34)$ and elderly $(n=58)$ tissues (females and males assessed together). In adult ascending/ descending colon, 1-20 Hz EFS usually caused contraction often followed by after-contraction on termination of EFS (figure 1A).
TTX $1 \mu \mathrm{M}$ prevented responses to $1-5 \mathrm{~Hz}$ EFS, but small monophasic contractions remained at higher frequencies (figure 1B). L-NAME $300 \mu \mathrm{M}$ prevented any relaxations and increased the amplitude of contractions during EFS. Atropine $1 \mu \mathrm{M}$ prevented contractions during EFS, revealing small muscle relaxations, particularly in ascending colon (figure 1B). Compared with adults, ascending colon from the elderly exhibited little-or-no muscle movement during 1-2 Hz EFS and contractions during 5-20 Hz appeared smaller (respectively $\mathrm{n}=19$, 32; there were no age-dependent differences in after-contractions), whereas in descending colon from the elderly, any effects of increasing age were unclear $(n=12-26$; online supplementary file 4$)$.

These small numbers of patients precluded meaningful statistical analyses. However, they supported initiation of a larger 


\begin{tabular}{|c|c|c|c|}
\hline \multirow[b]{2}{*}{ Variables } & \multicolumn{2}{|c|}{ Muscle relaxation } & \multirow[b]{2}{*}{$P$ value } \\
\hline & No $(n=49)$ & Yes $(n=60)$ & \\
\hline \multicolumn{4}{|l|}{ Medications } \\
\hline Regular laxative use & $3(6.1 \%)$ & $6(10.0 \%)$ & 0.51 \\
\hline Opiates & $7(14.3 \%)$ & $8(13.3 \%)$ & $0.89^{*}$ \\
\hline NSAIDs & $11(22.4 \%)$ & $13(21.7 \%)$ & $0.92^{*}$ \\
\hline Anticholinergic drugst & $5(10.2 \%)^{*}$ & $11(18.3 \%)$ & 0.28 \\
\hline Calcium channel blocker & $8(16.3 \%)$ & $13(21.7 \%)$ & $0.48^{*}$ \\
\hline Diuretics & $13(26.5 \%)$ & $13(21.7 \%)$ & $0.55^{*}$ \\
\hline Beta blocker & $9(18.4 \%)$ & $11(18.3 \%)$ & $1.00^{*}$ \\
\hline Anti-arrhythmics & 0 & $1(1.7 \%)$ & 1.00 \\
\hline Inhalers & $1(2.0 \%)$ & $8(13.3 \%)$ & 0.04 \\
\hline 5-alpha reductase inhibitor & $3(6.1 \%)$ & 0 & 0.09 \\
\hline Cation-containing agents & $11(22.4 \%)$ & $16(26.7 \%)$ & $0.61 *$ \\
\hline Bisphosphonates & $2(4.1 \%)$ & $4(6.7 \%)$ & 0.69 \\
\hline Anticonvulsants & 0 & $1(1.7 \%)$ & 1.00 \\
\hline Alpha blockers $\ddagger$ & $10(20.4 \%)$ & $2(3.3 \%)$ & 0.01 \\
\hline \multicolumn{4}{|l|}{ Medical history } \\
\hline Diverticular disease & $1(2.0 \%)$ & $5(8.3 \%)$ & 0.22 \\
\hline Previous abdominal or pelvic surgery & $12(24.5 \%)$ & $14(23.3 \%)$ & $0.89^{*}$ \\
\hline Conditions affecting central nervous system & $7(14.3 \%)$ & $10(16.7 \%)$ & $0.73^{*}$ \\
\hline Psychiatric conditions & $6(12.2 \%)$ & $4(6.7 \%)$ & 0.34 \\
\hline Diabetes mellitus & $10(20.4 \%)$ & $9(15.0 \%)$ & $0.46^{*}$ \\
\hline Any thyroid conditions & $2(4.1 \%)$ & $5(8.3 \%)$ & 0.46 \\
\hline Cardiovascular conditions & $12(24.5 \%)$ & $14(23.3 \%)$ & $0.89^{*}$ \\
\hline
\end{tabular}

The table shows the numbers of patients (with percentage of total) with each factor.

*Contingency comparisons are shown using Fisher's exact test or $\chi^{2}$ test (due to multiple comparisons, $p \leq 0.01$ considered statistically significant).

tMedications from different category but with similar action on certain receptor type.

FIncludes those used for cardiovascular and urinary indications.

EFS, electrical field stimulation; NSAIDs, non-steroidal anti-inflammatory drugs.

investigation in which EFS was applied at the single frequency of $5 \mathrm{~Hz}$, evoking a robust, TTX $(1 \mu \mathrm{M})$-sensitive muscle contraction or relaxation, usually followed by a large after-contraction (figure 1D). It was confirmed that atropine $1 \mu \mathrm{M}$ and L-NAME $300 \mu \mathrm{M}$ prevented, respectively, contractions and relaxations during EFS, enhancing the opposing response (figure 1D, table 2). Atropine also reduced the amplitude of any after-contractions, reduced further by $\mathrm{NK}_{1,2,3}$ receptor antagonism; MRS2500 $1 \mu \mathrm{M}$ had no consistent effects (table 2).

\section{Age-dependent changes in neuromuscular responses}

During EFS at $5 \mathrm{~Hz}$, the occurrence of contractions or relaxations sometimes varied among different muscle strips from the same colon (figure 1D). To investigate the effects of advancing age, a mean of 10 strips (3-31 from each patient, depending on tissue availability) were examined (239 patients). The numbers of strips relaxing or contracting during EFS, and contracting after EFS, were expressed as the percentage total for that patient (note: the number of strips used from each region of colon was similar and showed no age-dependent selection bias; data not shown).

Advancing age (35 to 91 years) increased the likelihood that muscle relaxation, rather than contraction, occurred during EFS in ascending colon (figure $2 \mathrm{~A}, \mathrm{C}$ ). In descending colon, there were no age-related changes in responses evoked during EFS (figure $2 \mathrm{~B}, \mathrm{C}$ ) and the incidence of after-contractions was unchanged in either region of colon (figure $2 \mathrm{C}$ ).
Multivariate logistic regression showed these results were largely uninfluenced by clinical variables with known potential to affect colon functions (table 3, online supplementary file 5) although use of $\alpha$-adrenoceptor antagonists appeared associated with reduced occurrence of muscle relaxation during EFS.

Subsequent studies to examine mechanisms of change were conducted using two discontinuous age groups (35-60 and $\geq 70$ years), either side of the median age.

\section{Mechanisms: anatomical}

Myenteric neuronal cell bodies staining for nNOS and ChAT

In 36 patients (8 adult, 9 elderly ascending; 9/10 adult/ elderly descending), a mean of $36 \mathrm{~mm}$ of myenteric plexus/ antibody/patient was sampled and 30306 myenteric neurons counted (646 sections). 18838 neurons were stained for $\mathrm{HuC} / \mathrm{D}$ (3520/3104 adult/elderly ascending, 6580/5634 descending), ChAT (5047 neurons, respectively, 827/1153 and 1711/1356) and nNOS (6421 neurons, respectively, 1627/1235 and 1743/1816). Reported changes were not influenced by interobserver differences (online supplementary file 1 ).

Figure $3 \mathrm{~A}$ shows examples of labelled sections; table 4 provides a summary. In adults, there appeared to be fewer myenteric ganglia and a smaller number of nerve cell bodies (corresponding to a smaller number of ChAT-staining cells) in ascending, relative to descending colon (respectively, $\mathrm{n}=8,9$ patients); these numbers did not change with increasing age (figure $3 \mathrm{~B}$; respectively, $n=9$, 10). Compared with other antibodies, the signal-to-background 


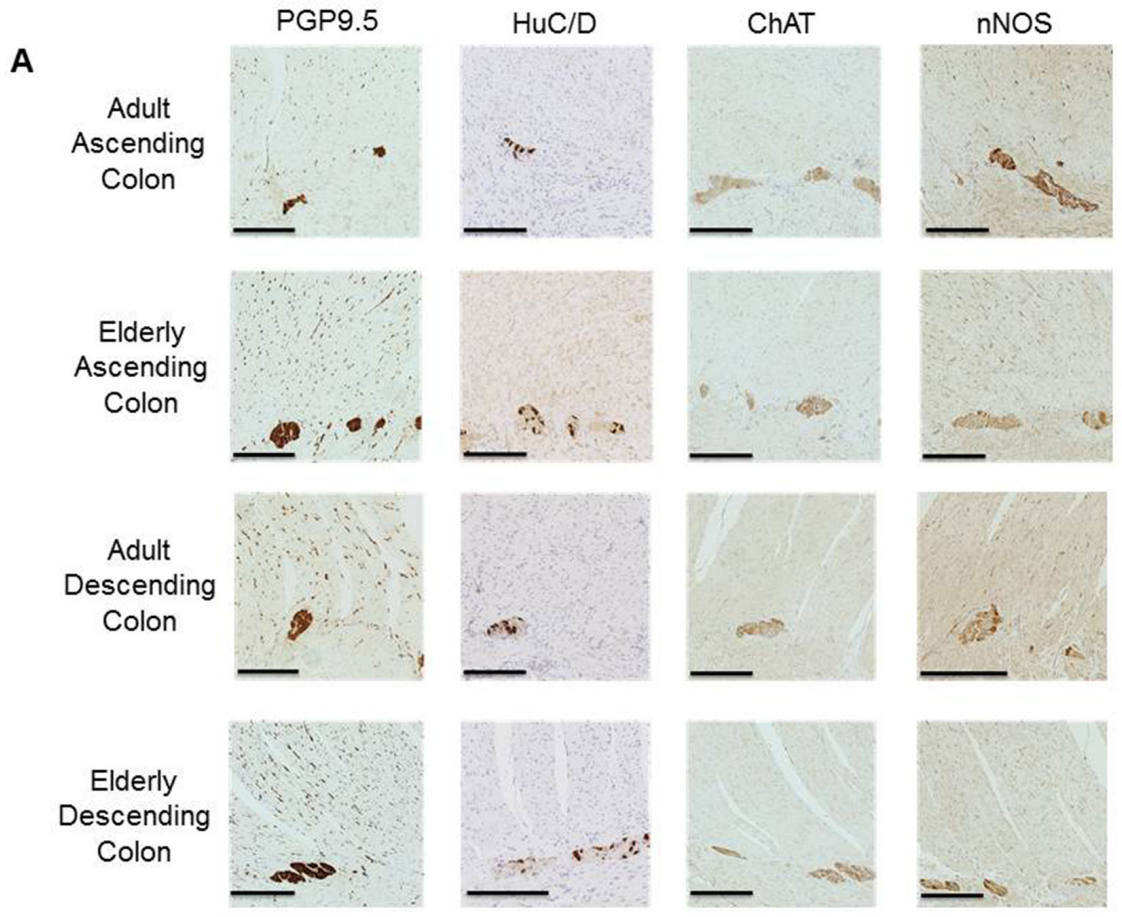

B

$$
\begin{aligned}
& \text { Ganglion number/ } \mathrm{mm} \\
& \text { myenteric plexus }
\end{aligned}
$$

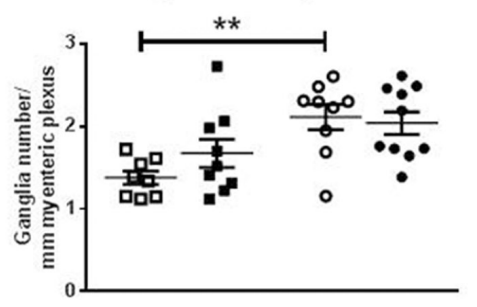

C Choline acetyltransferase/ $\mathrm{mm}$ myenteric plexus

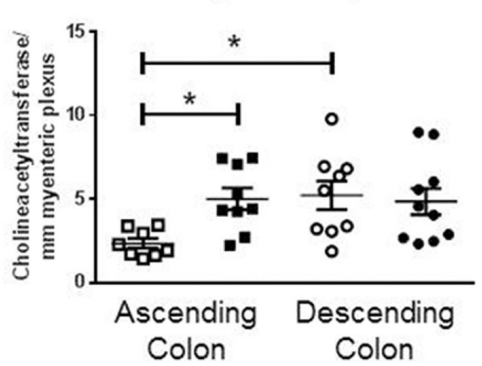

Nerve cell bodies/ $\mathrm{mm}$ myenteric plexus

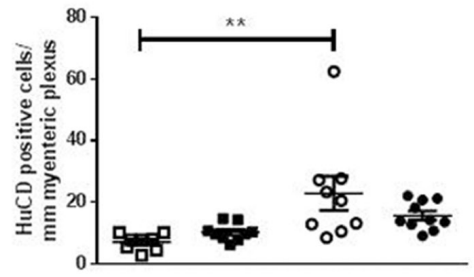

Neuronal nitric oxide synthase/ $\mathrm{mm}$ myenteric plexus

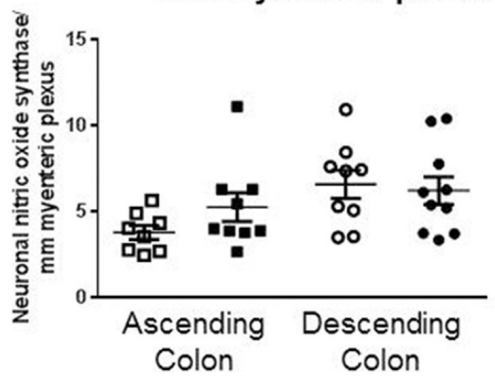

Figure 3 Expression of myenteric neuronal markers in ascending and descending colon. Panel A shows representative staining examples from the adult (35-60 years of age) and elderly group ( $\geq 70$ years) for each region of colon, using antibodies for human neuronal protein C/D (HuC/D), choline acetyltransferase (ChAT) and neuronal nitric oxide synthase (nNOS). Images were captured using NDP View version 2.3.1. Black scale bar is $250 \mu \mathrm{m}$. Counting was performed by two independent observers, and the values for each tissue are the mean of these counts. A ganglion was defined as a neural structure containing at least two neurons. The areas counted as neurons were between the circular and longitudinal muscle layers and represented areas of dark brown perikaryal staining in a cell that contained a nucleus (granular stain must cover the nucleus OR encircle at least $50 \%$ of circumference of the nucleus AND at least some cytoplasmic granular brown staining must be present). If the staining overlapped or appeared as a continuous area of dark brown staining, in the presence of two distinct nuclei and cell membranes, this was counted as two cell bodies; if there was ambiguity about the presence of a nucleus, the cell was not included. Panel B shows the number of ganglia and number of neuron cell bodies per millimetre of myenteric plexus (using the pan-neuronal cell body marker HuC/D) for adult ( $\square$ ) and elderly ( $\square$ ) ascending and descending (respectively 0 and $\bullet$ ) colon. Panel $C$ is arranged similarly and shows the numbers of neuron cell bodies per millimeter of myenteric plexus stained by the antibody for ChAT or nNOS. In Panels B and C, the data are expressed as means \pm SEM; $n=8$ adult ascending, 9 elderly ascending, 9 adult descending and 10 elderly descending colons for each stain. These were analysed using analysis of variance with Sidak's multiple comparison tests; ${ }^{*} \mathrm{P}<0.05$; ${ }^{*} \mathrm{P}<0.01$, only where indicated. PGP9.5, protein gene product 9.5 . 
Table 4 Summary of ganglia and cell bodies stained by antibodies for HuC/D, ChAT and nNOS per millimetre myenteric plexus in different regions of colon from patients of different age groups

\begin{tabular}{|c|c|c|c|c|}
\hline \multirow{2}{*}{$\begin{array}{l}\text { Numbers } \\
\text { per mm of } \\
\text { myenteric } \\
\text { plexus }\end{array}$} & \multicolumn{4}{|c|}{$\begin{array}{l}\text { Age group and region of colon } \\
\text { ( } n=\text { patients studied) }\end{array}$} \\
\hline & $\begin{array}{l}\text { Adult } \\
\text { ascending } \\
\text { (8) }\end{array}$ & $\begin{array}{l}\text { Elderly } \\
\text { ascending } \\
\text { (9) }\end{array}$ & $\begin{array}{l}\text { Adult } \\
\text { descending } \\
\text { (9) }\end{array}$ & $\begin{array}{l}\text { Elderly } \\
\text { descending } \\
\text { (10) }\end{array}$ \\
\hline $\begin{array}{l}\text { HuC/D ganglia/ } \\
\mathrm{mm}\end{array}$ & $1.4 \pm 0.1$ & $1.7 \pm 0.2$ & $2.1 \pm 0.2^{*}$ & $2.0 \pm 0.1$ \\
\hline $\begin{array}{l}\text { HuC/D neurons/ } \\
\mathrm{mm}\end{array}$ & $7.0 \pm 0.9$ & $10.2 \pm 0.9$ & $22.9 \pm 5.5^{*} \dagger$ & $15.7 \pm 1.5$ \\
\hline $\begin{array}{l}\text { ChAT neurons/ } \\
\mathrm{mm}\end{array}$ & $2.4 \pm 0.3$ & $5.0 \pm 0.6 \ddagger$ & $5.2 \pm 0.8 \S$ & $4.9 \pm 0.8$ \\
\hline $\begin{array}{l}\text { nNOS neurons/ } \\
\mathrm{mm}\end{array}$ & $3.8 \pm 0.4$ & $5.3 \pm 0.8$ & $6.6 \pm 0.8$ & $6.2 \pm 0.8$ \\
\hline
\end{tabular}

The data are expressed as means \pm SEM. Differences between the two age groups and regions of colon were analysed using analysis of variance with Sidak's multiple comparison tests.

${ }^{*} \mathrm{P}<0.01$ (between regions).

tNote the existence of an outlier observation among the HuC/D measurements (neurons $/ \mathrm{mm}$ ) in adult descending colon, which could not be excluded (see figure 3).

$\ddagger P<0.05$ (between age groups).

$\S \mathrm{P}<0.05$ (between regions).

ChAT, choline acetyltransferase; HuC/D, human neuronal protein C/D; nNOS, neuronal nitric oxide synthase.

differentiation for anti-ChAT was less strong. Nevertheless, in the elderly, the numbers of ChAT-immunolabelled neurons were consistently and significantly greater in ascending colon (figure 3C) but unchanged in descending colon. There were no statistically significant age-related differences in numbers of neurons expressing nNOS for either region (figure 3C). Post hoc calculation of statistical power (Stata SE v14.0) for the observed difference in ChAT immunostaining between adult and elderly ascending colon was 0.97 (expressed alternatively, only five patients would be required in each group to detect the observed difference with a power of 0.8 ). For the observed difference in $\mathrm{HuC} / \mathrm{D}$ staining between ascending and descending colon, the post hoc power was 0.82 .

\section{Densitometric analysis of intramuscular nerve fibre bundles}

In adults, the density of anti-PGP9.5 immunostaining within muscle was generally greater in descending, compared with ascending colon (figure 4B). In ascending colon of the elderly, the density of anti-PGP9.5 staining was unchanged compared with the adults. In descending colon of the elderly, the density was reduced only in deep circular muscle (figure 4B).

\section{Cholinergic enzymes}

In ascending colon there were no age-dependent differences in expression, specific activity or overall function of ChAT, although in descending colon ChAT function was greater in the elderly (expression unchanged), tending to increase specific activity (table 5). There were no age-dependent differences in $\mathrm{AChE}$ or BChE function in either region of colon (table 5).

\section{Mechanisms: functional}

Age-dependent/region-dependent reduction in cholinergic, not nitrergic functions

In ascending colon of both age groups, L-NAME $300 \mu \mathrm{M}$ increased the magnitude of cholinergically mediated contractions during EFS, but this was barely evident in descending colon; after-contractions were not significantly changed (figure 5 shows the magnitude of response; online supplementary file 6 shows percentage change). However, in ascending colon from the elderly, the increase in contractions was smaller compared with the adults $(p<0.05$; figure $5 \mathrm{C}$; ascending colon from, respectively, $n=14 / 25$ adult/elderly patients; descending colon from $16 / 23$ adult/elderly).

Atropine $1 \mu \mathrm{M}$ revealed or enhanced nitrergically mediated muscle relaxation and decreased the magnitude of after-contractions (figure 5D). Comparing the age groups, there were no statistically significant differences in magnitudes of muscle relaxations or after-contractions evoked by EFS during the presence of atropine, in either region of colon (figure 5F; ascending colon from, respectively, $n=6 / 6$ adult/elderly and descending colon from $8 / 5$ adult/elderly).

\section{No age-dependent changes in muscle function}

Advancing age did not influence contractions evoked by carbachol or Bay-K8644 in either region of colon (carbachol: respectively, $\mathrm{n}=7 / 7$ and $8 / 12$ ascending/descending colon from adult and elderly; Bay-K8644: $\mathrm{n}=5$ each), nor relaxations evoked by SNP (table 6).

\section{DISCUSSION}

This is the first large-scale study into the effects of advancing age on both neuromuscular anatomy and functions in human colon. It identified an age-dependent decline in cholinergic, not nitrergic, function but surprisingly, only in ascending colon. Paradoxically, the numbers of myenteric neurons staining positively for anti-ChAT increased in the same region, but there was no overall change in neuron count between adult and elderly patients.

The study was needed because human colon has important differences in anatomy and functions compared with mammals in which age research is usually conducted. ${ }^{1323}$ Further, in those age-related studies undertaken using human colon, data are inconsistent. ${ }^{14-16}$ This may be because small numbers were used, insufficient to overcome genetic differences and human variation (especially among the elderly, with longer exposure to lifestyle factors affecting bowel function). Inconsistencies are also created by studying only ascending or descending/sigmoid colon; each has different primary functions (respectively, fermentation of unabsorbed polysaccharides with water/nutrient absorption and storage of faeces prior to defection), embryological origin and molecular profile. ${ }^{24}$ Finally, to draw appropriate conclusions, analysis of changes in both anatomy and functions is desirable. Thus, the high reserve capacity of the enteric nervous system (ENS) (in animals ${ }^{5}$ ) means that functions of the whole organ are not represented by investigations into only structure (eg, neuron numbers) or functions of individual cell types.

The study began with a simple, large-scale assessment of the overall neuromuscular functions of ascending and descending colon, in which tissues were exposed to EFS at a frequency evoking clear neuronally mediated changes in muscle contractility. In adult colon from both regions EFS usually caused contraction, followed by 'after-contraction' on termination of the stimulus. The contraction during EFS was cholinergically mediated, attenuated by simultaneous inhibitory nitrergic activation, their dominance being consistent with greater numbers of myenteric neurons in human colon staining for ChAT or nNOS. ${ }^{25}$ However, in the elderly, EFS was increasingly likely to evoke muscle relaxation in ascending colon. This difference 
A

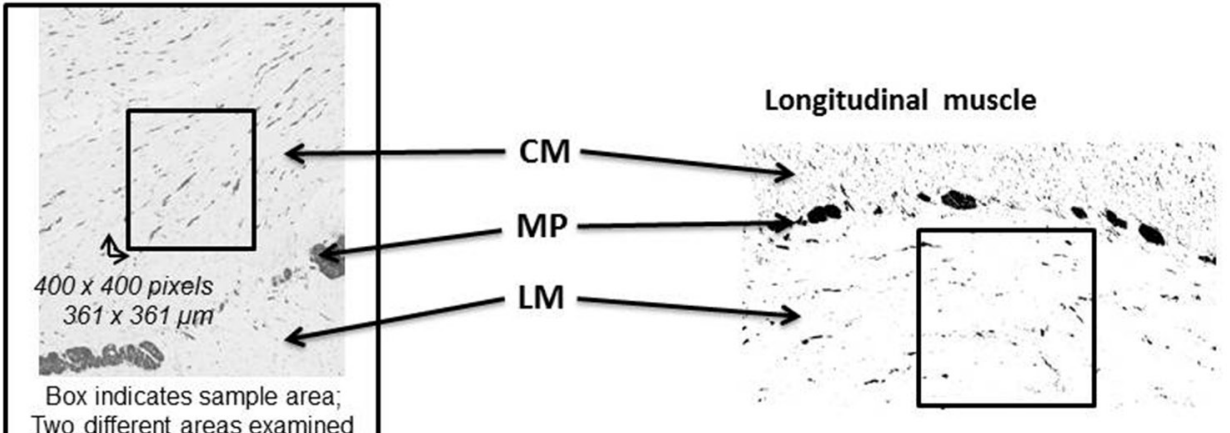

Two different areas examined

for each region, in each of 4

sections from each patient

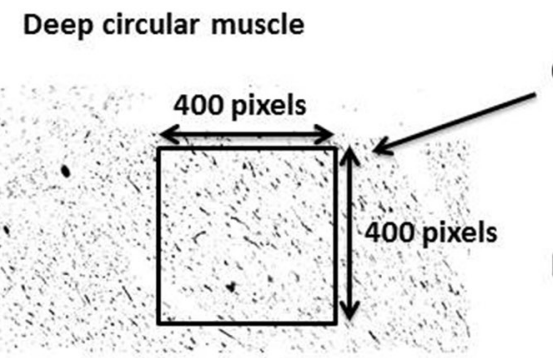

B

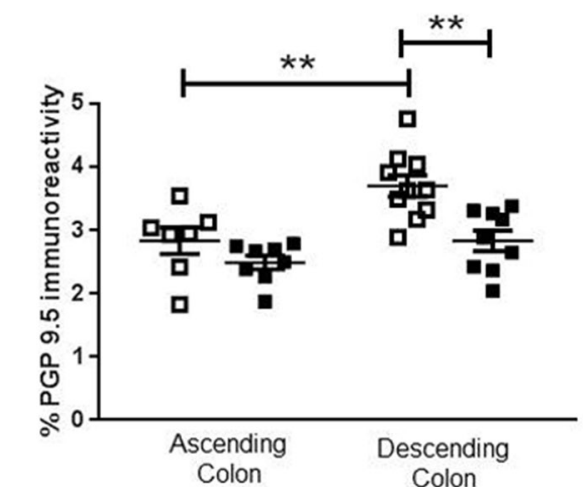

Longitudinal muscle

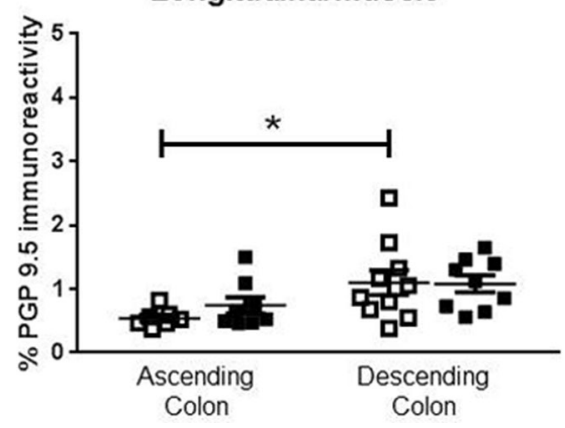

Circular muscle near the myenteric plexus

$\mathrm{CM}$

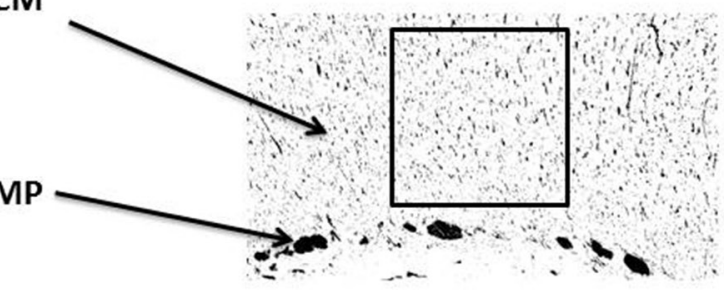

Circular muscle nearto myenteric plexus

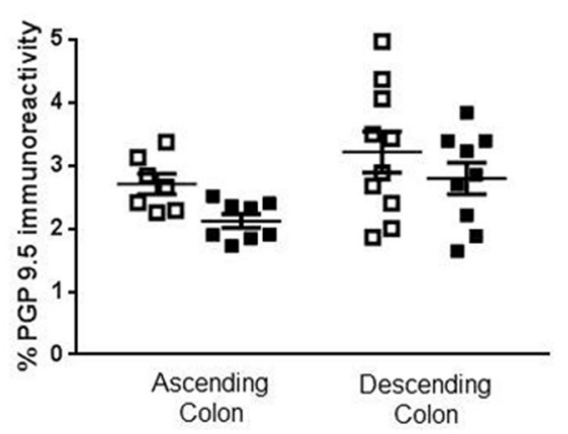

Figure 4 Density of neuronal innervation within muscle layers. Panel A shows representative examples from protein gene product 9.5 (PGP9.5) stained paraffin-embedded sections of human colon muscle. Images were captured using NDP View version 2.3.1. Densiometric analysis was performed on filtered images converted to black and white, and the percentage density of staining measured over $400 \times 400$ pixel excerpts, as shown in the boxes, from the circular muscle (CM) near the myenteric plexus (MP), the deeper CM and the longitudinal muscle (LM), on a fixed magnification of 10x, using ImageJ. For each patient, four sections were analysed and for each region of muscle, two different fields were examined in each of the four sections by two separate assessors. Panel B shows the density of PGP9.5-positive nerve fibres in the adult (35-60 years of age; $\square$ ) and elderly $(\geq 70$ years; $\square$ ) groups within ascending and descending colon, $n=7$ adult and $n=8$ elderly ascending colon and, respectively, 10 and 9 adult and elderly descending colon. Both assessors identified the same statistically significant changes or trends in the elderly (online supplementary data file 1). These data are expressed as means \pm SEM and were analysed using analysis of variance with Sidak's multiple comparison test, ${ }^{*} P<0.05 ;{ }^{*} P<0.01$. 
Table 5 The expression and function of choline acetyltransferase, acetylcholinesterase and butyrylcholinesterase

\begin{tabular}{|c|c|c|c|c|}
\hline & Age group & Ascending & Descending & Region comparison (adult) \\
\hline \multicolumn{5}{|l|}{ Choline acetyltransferase (ChAT) } \\
\hline \multirow[t]{3}{*}{ ChAT function (pmol/min/mg) } & $35-60$ years & $687 \pm 65(8)$ & $567 \pm 83(10)$ & \multirow[t]{3}{*}{$P$ value $=0.64$} \\
\hline & $\geq 70$ years & $688 \pm 76(10)$ & $890 \pm 71(10)$ & \\
\hline & Age comparison & $P$ value $=1.00$ & $P$ value $=0.01$ & \\
\hline \multirow[t]{2}{*}{ ChAT expression (ng/mg) } & $35-60$ years & $12.1 \pm 2.0(8)$ & $9.0 \pm 0.9(9)$ & \multirow[t]{2}{*}{$P$ value $=0.27$} \\
\hline & $\geq 70$ years & $12.2 \pm 1.1(10)$ & $10.1 \pm 0.9(10)$ & \\
\hline \multirow{2}{*}{$\begin{array}{l}\text { ChAT specific activity (pmol/ } \\
\mathrm{ng} / \mathrm{min} \text { ) }\end{array}$} & $\geq 70$ years & $63 \pm 10(10)$ & $97 \pm 12(10)$ & \multirow{2}{*}{$P$ value $=1.00$} \\
\hline & Age comparison & $P$ value $=1.00$ & $P$ value $=0.21$ & \\
\hline \multicolumn{5}{|l|}{ Acetyl cholinesterase (AChE) } \\
\hline \multirow[t]{2}{*}{ AChE function (nmol/min/mg) } & $35-60$ years & $1045 \pm 379(7)$ & $700 \pm 132(8)$ & \multirow[t]{2}{*}{$P$ value $=0.65$} \\
\hline & $\geq 70$ years & $451 \pm 160(8)$ & $590 \pm 196(7)$ & \\
\hline \multirow{3}{*}{$\begin{array}{l}\text { AChE specific activity (nmol/ } \\
\mathrm{min} / \mathrm{mg} \text { ) }\end{array}$} & $35-60$ years & $221 \pm 46(7)$ & $251 \pm 20(7)$ & \multirow[t]{3}{*}{$P$ value $=0.96$} \\
\hline & $\geq 70$ years & $199 \pm 66(8)$ & $207 \pm 37(7)$ & \\
\hline & Age comparison & $P$ value $=0.98$ & $P$ value $=0.89$ & \\
\hline \multicolumn{5}{|l|}{ Butryl cholinesterase (BChE) } \\
\hline \multirow[t]{3}{*}{ BChE function $(\mathrm{nmol} / \mathrm{min} / \mathrm{mg})$} & $35-60$ years & $967 \pm 295(7)$ & $620 \pm 103(10)$ & \multirow[t]{3}{*}{$P$ value $=0.42$} \\
\hline & $\geq 70$ years & $796 \pm 197(9)$ & $556 \pm 75(10)$ & \\
\hline & Age comparison & $P$ value $=0.87$ & $P$ value $=0.99$ & \\
\hline \multirow[t]{3}{*}{ BChE expression (ng/mg) } & $35-60$ years & $573 \pm 140(8)$ & $325 \pm 84(10)$ & \multirow[t]{3}{*}{$P$ value $=0.16$} \\
\hline & $\geq 70$ years & $352 \pm 70(10)$ & $292 \pm 45(10)$ & \\
\hline & Age comparison & $P$ value $=0.24$ & $P$ value $=0.99$ & \\
\hline
\end{tabular}

Assays were performed in muscle biopsies taken from patients undergoing resections of the ascending or descending colon. The $n$ values are in parenthesis.

was largely uninfluenced by concurrent disease or medications, systematically analysed (unlike previous studies) as potentially confounding covariates. Thus, although it remains a possibility that other factors not measured could have influenced the data (eg, poor glycaemic control, inclusion of premenopausal/postmenopausal women among the younger group, asymptomatic diverticulosis), it seems reasonable to conclude that the data support an age-dependent change in neuromuscular functions in ascending but surprisingly not in descending colon.

Additional substudies were conducted to determine the mechanisms of change in the same cohort of patients. First, we looked for changes in numbers and phenotype of myenteric neurons. Counting of neurons requires strict application of defined criteria, ${ }^{18}$ performed blind to subject status. In this study, 30306 myenteric neurons were counted in 36 patients; anti-HuC/D and anti-PGP9.5 assessed, respectively, myenteric ganglia/neuron cell bodies and density of nerves within the muscle. This represents the largest quantitative measurement of ENS neurons so far reported. ${ }^{26}$ The results indicated that descending colon had greater numbers of myenteric neuron cell bodies, and density of PGP9.5 staining within the muscle, compared with ascending colon (consistent with previous studies ${ }^{26}$ ), and increasing age did not change these numbers. However, others reported a decline in numbers of myenteric ganglia and neurons in elderly human colon $^{27}$ and small intestine. ${ }^{28}$ The relatively small numbers of tissues studied and different staining techniques may explain this difference. In the largest previous study, Bernard et $a l^{14}$ found a decline in numbers of myenteric neuron cell bodies in descending and sigmoid colon staining for $\mathrm{HuC} / \mathrm{D}$, ChAT and PGP9.5, but no change in numbers of cell bodies staining for nNOS. Here, the different findings may be attributed to differences in method (whole mount vs paraffin sections) and/or presentation of data. In our study, we compared two age groups. Bernard et al tested for linear trends, with most patients showing similar numbers of $\mathrm{HuC} / \mathrm{D}$-staining neurons. In spite of the decline in neuron cell bodies, these authors found no age-dependent changes in density of PGP9.5 staining of intramuscular axon bundles.

In the present study, there were relatively more nNOS-staining neurons within ascending colon (confirming others ${ }^{25}$ ), but no age-related changes in ascending or descending colon. These data are consistent with the suggestion that enteric nitrergic neurons do not exhibit age-related loss. ${ }^{629}$ In unspecified regions of colon from patients of advanced age, others report higher percentage of nitrergic neurons with no changes in numbers of calretinin-expressing neurons. ${ }^{16}$

The present study indicates that ChAT is found in $\sim 30 \%$ of myenteric neurons within human colon (others suggest $41 \%-48 \%{ }^{25}$; perhaps the difference reflects the quality of antibodies used and the counting criteria). A surprising finding was that in ascending, not descending colon, the numbers of nerve cell bodies detected by anti-ChAT increased in the elderly, seemingly contrasting with a generally held view that in rodents, enteric cholinergic neurons 
A

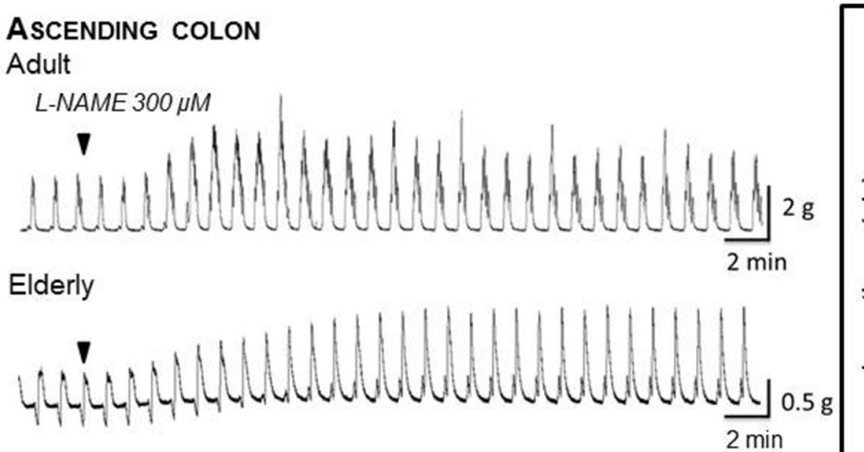

B

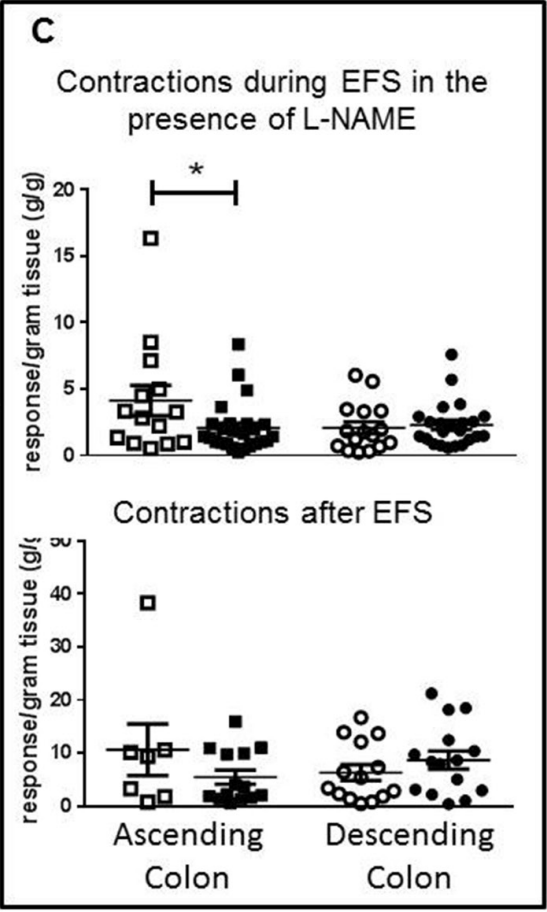

D

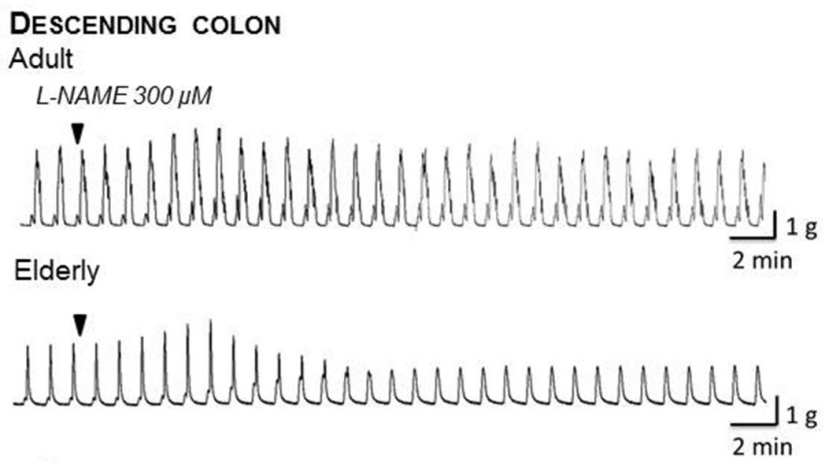

ASCENDING COLON

Adult
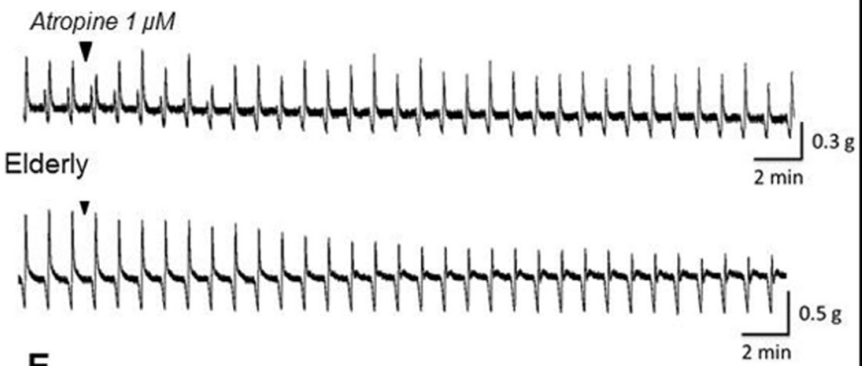

E

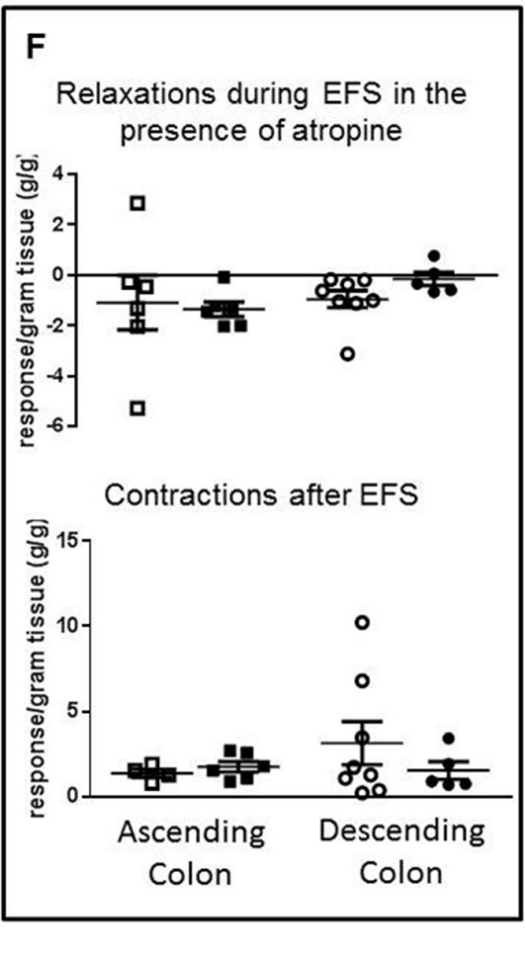

Figure 5 Age-dependent changes in cholinergic and nitrergic responses to electrical field stimulation (EFS) in human ascending and descending colon. EFS was applied at $5 \mathrm{~Hz}$ and at $50 \mathrm{~V}$ for $10 \mathrm{~s}$ every $1 \mathrm{~min}$, in the absence and presence of $\mathrm{N}_{\omega}$-nitro-L-arginine methyl ester hydrochloride (L-NAME) $300 \mu \mathrm{M}$ or atropine $1 \mu \mathrm{M}$. Panels $A$ and D show examples of original traces showing the effects of, respectively, L-NAME and atropine in the adult and elderly ascending colon. Similarly, panels B and E show examples of original traces for both treatments in the adult and elderly descending colon. Panels $C$ and $F$ show the data for each treatment in each region of adult (35-60 years of age; $\square$ ) and elderly ( $\geq 70$ years; $\square$ ) colon, for each tissue tested. The data are expressed as $\mathrm{g}$ tension/g wet weight of tissue, generated during and after termination of EFS, together with the mean \pm SEM contractile force. Respectively, $n=14 / 6$ and $7 / 4$ (response generated during/after termination of EFS in the presence of L-NAME and atropine for adult ascending colon), 25/6 and 14/6 (elderly ascending colon), 16/8 and 14/8 (adult descending colon) and 23/5 and 15/5 (elderly descending colon); note that after-contractions did not always occur so their $n$ values are smaller than for the responses measured during EFS. These were analysed using analysis of variance with Sidak's multiple comparison tests; ${ }^{*} \mathrm{P}<0.05$ only where indicated. 
Table 6 Contractions and relaxations of the muscle in adult (35-60 years of age) and elderly ( $\geq 70$ years) human ascending and descending colon

\begin{tabular}{|c|c|c|c|c|}
\hline & \multicolumn{2}{|l|}{ Ascending } & \multicolumn{2}{|l|}{ Descending } \\
\hline & Adult & Elderly & Adult & Elderly \\
\hline \multicolumn{5}{|c|}{ Compounds causing muscle contraction* } \\
\hline $\begin{array}{l}\text { Carbachol } \\
0.001-10 \mu \mathrm{M}\end{array}$ & $\begin{array}{l}p \mathrm{EC}_{50}=6.5 \pm 0.5 \\
\mathrm{E}_{\max }=50 \pm 10 \mathrm{~g} / \mathrm{g} \\
\mathrm{n}=7\end{array}$ & $\begin{array}{l}p \mathrm{EC}_{50}=6.2 \pm 0.3 \\
\mathrm{E}_{\max }=43 \pm 6 \mathrm{~g} / \mathrm{g} \\
\mathrm{n}=8\end{array}$ & $\begin{array}{l}p \mathrm{EC}_{50}=6.4 \pm 0.2 \\
\mathrm{E}_{\max }=53 \pm 5 \mathrm{~g} / \mathrm{g} \\
\mathrm{n}=7\end{array}$ & $\begin{array}{l}p \mathrm{EC}_{50}=7.0 \pm 0.4 \\
\mathrm{E}_{\max }=45 \pm 6 \mathrm{~g} / \mathrm{g} \\
\mathrm{n}=12\end{array}$ \\
\hline $\begin{array}{l}\text { Bay-K8644 } 1 \mu \mathrm{M} \\
\text { (in presence of L-NAME } 300 \mu \mathrm{M} \text { ) }\end{array}$ & $\begin{array}{l}16 \pm 7 g / g \\
n=5\end{array}$ & $\begin{array}{l}17 \pm 8 \mathrm{~g} / \mathrm{g} \\
\mathrm{n}=5\end{array}$ & $\begin{array}{l}25 \pm 9 g / g \\
n=5\end{array}$ & $\begin{array}{l}13 \pm 3 g / g \\
n=5\end{array}$ \\
\hline \multicolumn{5}{|l|}{ Compound causing muscle relaxation } \\
\hline $\begin{array}{l}\text { SNPt } \\
0.01-1000 \mu \mathrm{M}\end{array}$ & $\begin{array}{l}p \mathrm{EC}_{50}=6.5 \pm 0.8 \\
\mathrm{E}_{\max }=1.7 \pm 0.2 \mathrm{~g} / \mathrm{g} \\
\mathrm{n}=7\end{array}$ & $\begin{array}{l}p \mathrm{EC}_{50}=6.4 \pm 0.6 \\
\mathrm{E}_{\max }=1.9 \pm 0.2 \mathrm{~g} / \mathrm{g} \\
\mathrm{n}=10\end{array}$ & $\ddagger$ & $\ddagger$ \\
\hline
\end{tabular}

Data are expressed as mean \pm SEM muscle tension/g of tissue (when using the single concentration of Bay-K8644) or when concentration-response curves were constructed, as the $p \mathrm{EC}_{50}$ and $\mathrm{E}_{\text {max }}$ values derived from these curves (see online supplementary file 3 for carbachol concentration-response curves in female/male, adult/elderly ascending and descending colon). There were no statistically significant differences between values obtained using adult ascending and descending colon or when these values were compared with the elderly ( $p>0.10$ each).

*For comparison, in adult ascending and descending colon in the presence of L-NAME $300 \mu \mathrm{M}$, EFS generated, respectively, $4.1 \pm 1.1$ and $2.1 \pm 0.5 \mathrm{~g}$ tension $/ \mathrm{g}$, approximately equivalent to the contraction evoked by, respectively, 60 and $4 \mathrm{nM}$ carbachol ( $\sim \mathrm{EC}$, and $\mathrm{EC}_{4}$ values).

TThe effects of SNP were uninfluenced by breakdown in the presence of haemoglobin to form cyanide and methaemoglobin in addition to NO (each can affect tissue viability) thus, the magnitude of relaxation evoked by SNP $100 \mu \mathrm{M}$ in ascending colon was not different to that evoked by the NO donor, diethylamine NONOate $10 \mu \mathrm{M}$ (respectively, $1.3 \pm 0.5$ and $1.4 \pm 0.4 \mathrm{~g} / \mathrm{g}, \mathrm{n}=6$ each, $\mathrm{p}>0.8$.

¥Consistent, concentration-dependent relaxations could not be obtained in descending colon.

EFS, electrical field stimulation; L-NAME, $\mathrm{N}_{\omega}$-nitro-L-arginine methyl ester hydrochloride; NO, nitric oxide; SNP, sodium nitroprusside.

are lost with increasing age. ${ }^{6}$ Further experiments, in which ChAT, $\mathrm{AChE}$ and $\mathrm{BChE}$ were extracted from human colon, showed no consistent age-dependent differences in overall expression, specific activity or function. Similarly in rat colon, cholinesterase activities were unchanged by advancing age. ${ }^{30}$ Thus, these data, together with unchanged myenteric neuron cell bodies numbers, may be explained not by increased synthesis of ChAT, but by its increased presence within cell bodies of existing neurons. ChAT is synthesised in the soma of cholinergic neurons and transported to the terminals for ACh synthesis. ${ }^{31}$ In age-related neurodegeneration, impaired axonal transport and/or axonal dysfunction are among the earliest changes. ${ }^{30-33}$ Similarly, in mice exposed to the neurotoxic agent 5-fluorouracil, a decline in numbers of enteric ChAT-immunoreactive and other neurons was preceded by increased number of ChAT-immunoreactive neurons. ${ }^{34}$ In the present experiments, the increased detection of ChAT-immunoreactive cell bodies may therefore reflect reduced axonal transport of the enzyme away from the cell body following age-related damage to axonal transport. Experiments are required to test this hypothesis. The relatively poor signal-to-background for the ChAT antibody precludes meaningful analysis of ChAT expression by nerve terminals within the muscle, but perhaps choline uptake/ACh release could be measured during nerve stimulation in human colon.

In the first of additional functional studies, cholinergic and nitrergic functions were isolated by, respectively, L-NAME and atropine. During the presence of L-NAME, cholinergically mediated contractions evoked by EFS in ascending colon from the elderly were smaller compared with adults. A similar difference was not observed in descending colon. In the presence of atropine, nitrergically mediated relaxations were not changed with increasing age in either region of colon. These data suggest that the age-related changes in function observed in the larger functional study (see above) were due to region-dependent decline in cholinergic function, which in ascending colon enabled an intact nitrergic function to become dominant. This change was not due to reduced ability of the muscle to contract (in response to carbachol or Bay-K8644, also refuting the possibility of compensatory age-dependent changes in muscarinic receptor density ${ }^{35}$ ) or relax (in response to SNP). Others ${ }^{15}$ reported a greater maximal response to carbachol in sigmoid colon from females, compared with males ( $\sim 60$ years), with elderly females (mid-late 70 s) being more sensitive; by contrast, EFS-evoked contractions and the effect of L-NAME on these responses were greater in elderly males. However, several muscle strips were used from the same patient, $\mathrm{n}$ values representing numbers of preparations, not patients; the potential for unintentional bias is therefore high. The present data also contrast with a reported age-dependent increase in ability of human colon muscle cells to contract in response to different ligands, including carbachol ${ }^{36}$; perhaps enzyme digestion influences how cells respond.

In summary, the size and design of the study aimed to accept, control and understand state and trait variability. The data (1) represent the most complete set of normative data for the human ENS (a recent systematic review identified marked diversity in quantification of human ENS markers among numerous small studies $\left.{ }^{26}\right),(2)$ refute previous observations with smaller numbers of patients, notably the existence of age-related changes in muscle function ${ }^{15}$ and in neuron numbers within the colon, ${ }^{16}$ (3) pose a new hypothesis meriting further study, namely that a region-dependent decline in cholinergic functions could be associated with increased somal ChAT staining caused by reduced axonal transport and (4) indicate that findings from laboratory animals do not always translate to humans, species-dependent variability 3538 being additionally hampered by gross differences in lower bowel anatomy ${ }^{13}$ and failure to consider that different bowel regions may age differently. Several questions remain unanswered. What causes the loss of cholinergic function and why only in ascending colon? Possible mechanisms include age-related intestinal inflammation, ${ }^{39}$ susceptibility to reactive oxygen species and loss of trophic support from glial cells. ${ }^{40}$ In the present study, there was no age-associated difference in gross inflammatory status, but more sensitive measurements are needed (eg, assessment of age-dependent changes in 'proinflammatory' status of macrophages ${ }^{41}$ and analysis of immune activity of dendritic cell subsets in different regions of human colon ${ }^{42}$ ). Interestingly, the high content of living bacteria in ascending colon may change in composition among the elderly, promoting low-grade inflammation (inflammaging) ${ }^{43}$ and increasing 
mucosal permeability to allow potentially damaging substances to penetrate into the wall of ascending colon. Precedents for age-related, region-specific reductions in cholinergic functions (and increased ChAT; see Discussion above) exist in brain of patients with mild cognitive impairment ${ }^{4445}$ and in aged rats. ${ }^{46}$

Notably, none of the patients studied had previous clinical diagnosis of constipation (any history of self-reporting constipation was not obtained). It is, therefore, not possible to conclude that declined myenteric cholinergic function within the ascending colon necessarily leads to clinical constipation. Indeed, other degenerative changes are suggested to contribute to age-related constipation (including changes in inhibitory junction potentials within the descending colon ENS, ${ }^{47}$ enteric sensory ${ }^{5}$ and extrinsic sensory innervations ${ }^{48}$ ). Nevertheless, the reduced cholinergic function does support the view that the ENS reserve capacity is reduced in the elderly, increasing sensitivity to lifestyle changes affecting intestinal functions (eg, diet, exercise, medications; see the Introduction section) and raising the probability of developing constipation. A similar argument has been suggested for cholinergic function in the aged brain, in which the consequence of a gradual decline in synthesis and/or release of ACh from synaptosomes ${ }^{49}$ only becomes apparent when nerves are stressed or damaged. ${ }^{31}$

Acknowledgements We thank other consultant colorectal surgeons, particularly Chris Chan, and pathologists at Barts Health for assisting with identification of patients for recruitment into this study and for providing tissue suitable for laboratory use.

Contributors JB and VWSK conducted the experiments, SE and CHK facilitated the identification, collection and governance of human tissue collection, TD-S, JEM and MJS provided methodology guidance, GJS wrote the manuscript and all authors participated in its construction and refinement, particularly CHK, VWSK, JB and MJS.

Funding JB was supported by the Bowel and Cancer research charity, the Dunhill Medical Trust (grant no: R382/1114 to GJS, CHK and MJS) and an EMBO scholarship to visit the Karolinska Institutet (to JB). VWSK was supported by the research into ageing fund, set up and managed by AgeUK (grant to GJS). AP and SE are supported by Takeda Pharmaceuticals.

Competing interests GJS is currently in receipt of funding from Takeda Pharmaceuticals, BBSRC together with GlaxoSmithKline, Benevolent and the Dunhill Foundation. He acts as an advisor to Takeda Pharmaceuticals and to Zealand Pharma.

\section{Patient consent Not required.}

Ethics approval Approved by the local ethics committee (REC 10/H0703/71).

Provenance and peer review Not commissioned; externally peer reviewed.

Open access This is an open access article distributed in accordance with the Creative Commons Attribution Non Commercial (CC BY-NC 4.0) license, which permits others to distribute, remix, adapt, build upon this work non-commercially, and license their derivative works on different terms, provided the original work is properly cited, appropriate credit is given, any changes made indicated, and the use is non-commercial. See: http://creativecommons.org/licenses/by-nc/4.0/.

\section{REFERENCES}

1 Camilleri M, Lee JS, Viramontes B, et al. Insights into the pathophysiology and mechanisms of constipation, irritable bowel syndrome, and diverticulosis in older people. J Am Geriatr Soc 2000;48:1142-50.

2 Gallagher P, O'Mahony D. Constipation in old age. Best Pract Res Clin Gastroenterol 2009;23:875-87.

3 McCrea GL, Miaskowski C, Stotts NA, et al. A review of the literature on gender and age differences in the prevalence and characteristics of constipation in North America. J Pain Symptom Manage 2009;37:737-45.

4 O'Mahony D, O'Leary P, Quigley EM. Aging and intestinal motility: a review of factors that affect intestinal motility in the aged. Drugs Aging 2002;19:515-27.

5 Wade PR. Aging and neural control of the GI tract. I. Age-related changes in the enteric nervous system. Am J Physiol Gastrointest Liver Physiol 2002;283:G489-95.

6 Phillips RJ, Powley TL. Innervation of the gastrointestinal tract: patterns of aging. Auton Neurosci 2007:136:1-19.

7 Gamage PP, Ranson RN, Patel BA, et al. Myenteric neuron numbers are maintained in aging mouse distal colon. Neurogastroenterol Motil 2013;25:e495-505.

8 Yuan R, Peters LL, Paigen B. Mice as a mammalian model for research on the genetics of aging. Ilar / 2011;52:4-15.
9 Sanger GJ, Holbrook JD, Andrews PL. The translational value of rodent gastrointestinal functions: a cautionary tale. Trends Pharmacol Sci 2011;32:402-9.

10 Keane TM, Goodstadt L, Danecek P, et al. Mouse genomic variation and its effect on phenotypes and gene regulation. Nature 2011:477:289-94.

11 Wu M, Van Nassauw L, Kroese AB, et al. Myenteric nitrergic neurons along the rat esophagus: evidence for regional and strain differences in age-related changes. Histochem Cell Biol 2003;119:395-403.

12 Tran L, Greenwood-Van Meerveld B. In a non-human primate model, aging disrupts the neural control of intestinal smooth muscle contractility in a region-specific manner. Neurogastroenterol Motil 2014;26:410-8.

13 Furness JB, Cottrell JJ, Bravo DM. Comparative gut physiology symposium: comparative physiology of digestion. J Anim Sci 2015;93:485-91.

14 Bernard CE, Gibbons SJ, Gomez-Pinilla PJ, et al. Effect of age on the enteric nervous system of the human colon. Neurogastroenterol Motil 2009;21:746-e46.

15 Maselli MA, Trisolini P, Demma I, et al. Gender- and age-related differences in muscular and nerve-mediated responses in human colon. Dig Dis Sci 2011;56:352-8.

16 Belai A, Burnstock $G$. Distribution and colocalization of nitric oxide synthase and calretinin in myenteric neurons of developing, aging, and Crohn's disease human small intestine. Dig Dis Sci 1999;44:1579-87.

17 Feakins RM. British Society of Gastroenterology. Inflammatory bowel disease biopsies: updated British Society of Gastroenterology reporting guidelines. J Clin Pathol 2013;66:1005-26.

18 Kapur RP. Counting neurons is not as easy as 'one-two, three'. Neurogastroenterol Motil 2013;25:549-53.

19 Swaminathan M, Kapur RP. Counting myenteric ganglion cells in histologic sections: an empirical approach. Hum Pathol 2010;41:1097-108.

20 Broad J, Kung VW, Boundouki G, et al. Cholinergic interactions between donepezil and prucalopride in human colon: potential to treat severe intestinal dysmotility. $\mathrm{Br} J$ Pharmacol 2013;170:1253-61.

21 Broad J, Maurel D, Kung VW, et al. Human native kappa opioid receptor functions not predicted by recombinant receptors: Implications for drug design. Sci Rep 2016;6:30797

22 Mañé N, Gil V, Martínez-Cutillas M, et al. Differential functional role of purinergic and nitrergic inhibitory cotransmitters in human colonic relaxation. Acta Physiol 2014;212:293-305.

23 Sanger GJ, Broad J, Kung V, et al. Translational neuropharmacology: the use of human isolated gastrointestinal tissues. Br J Pharmacol 2013;168:28-43.

24 Phillips SF. Functions of the large bowel: an overview. Scand I Gastroenterol Suppl 1984:93(suppl):1-12.

25 Wattchow D, Brookes S, Murphy E, et al. Regional variation in the neurochemical coding of the myenteric plexus of the human colon and changes in patients with slow transit constipation. Neurogastroenterol Motil 2008;20:1298-305.

26 Knowles $\mathrm{CH}$, Veress B, Kapur RP, et al. Quantitation of cellular components of the enteric nervous system in the normal human gastrointestinal tract--report on behalf of the Gastro 2009 International Working Group. Neurogastroenterol Motil 2011:23:115-24.

27 Gomes OA, de Souza RR, Liberti EA. A preliminary investigation of the effects of aging on the nerve cell number in the myenteric ganglia of the human colon. Gerontology 1997:43:210-7.

28 de Souza RR, Moratelli HB, Borges N, et al. Age-induced nerve cell loss in the myenteric plexus of the small intestine in man. Gerontology 1993;39:183-8.

29 Santer RM. Survival of the population of NADPH-diaphorase stained myenteric neurons in the small intestine of aged rats. J Auton Nerv Syst 1994;49:115-21.

30 Tezuka A, Ishihata A, Aita T, et al. Aging-related alterations in the contractile responses to acetylcholine, muscarinic cholinoceptors and cholinesterase activities in jejunum and colon of the male Fischer 344 rats. Exp Gerontol 2004;39:91-100.

31 Terry AV, Buccafusco JJ. The cholinergic hypothesis of age and Alzheimer's diseaserelated cognitive deficits: recent challenges and their implications for novel drug development. J Pharmacol Exp Ther 2003:306:821-7.

32 Adalbert R, Coleman MP. Review: Axon pathology in age-related neurodegenerative disorders. Neuropathol App/ Neurobiol 2013:39:90-108.

33 Millecamps S, Julien JP. Axonal transport deficits and neurodegenerative diseases. Nat Rev Neurosci 2013;14:161-76.

34 McQuade RM, Stojanovska V, Donald E, et al. Gastrointestinal dysfunction and enteric neurotoxicity following treatment with anticancer chemotherapeutic agent 5-fluorouracil. Neurogastroenterol Motil 2016:28:1861-75.

35 Roberts D, Gelperin D, Wiley JW. Evidence for age-associated reduction in acetylcholine release and smooth muscle response in the rat colon. Am J Physiol 1994;267:G515-22.

36 Boyer JC, Guitton C, Pignodel C, et al. Differential responsiveness to contractile agents of isolated smooth muscle cells from human colons as a function of age and inflammation. Dig Dis Sci 1997;42:2190-6.

37 Hoyle CH, Saffrey MJ. Effects of aging on cholinergic neuromuscular transmission in isolated small intestine of ad libitum fed and calorically-restricted rats. Neurogastroenterol Motil 2012;24:586-92.

38 Abalo R, Vera G, Rivera AJ, et al. Age-related changes in the gastrointestinal tract: a functional and immunohistochemical study in guinea-pig ileum. Life Sci 2007;80:2436-45. 
39 Schiffrin EJ, Morley JE, Donnet-Hughes A, et al. The inflammatory status of the elderly: the intestinal contribution. Mutat Res 2010;690:50-6.

40 Thrasivoulou C, Soubeyre V, Ridha H, et al. Reactive oxygen species, dietary restriction and neurotrophic factors in age-related loss of myenteric neurons. Aging Cell 2006;5:247-57.

41 Becker L, Nguyen L, Gill J, et al. Age-dependent shift in macrophage polarisation causes inflammation-mediated degeneration of enteric nervous system. Gut 2018:67:827-36

42 Bernardo D, Durant L, Mann ER, et al. Chemokine (C-C Motif) Receptor 2 mediates dendritic cell recruitment to the human colon but is not responsible for differences observed in dendritic cell subsets, phenotype, and function between the proximal and distal colon. Cell Mol Gastroenterol Hepatol 2016:2:22-39

43 Biagi E, Nylund L, Candela M, et al. Through ageing, and beyond: gut microbiota and inflammatory status in seniors and centenarians. PLoS One 2010;5:e10667.
44 DeKosky ST, Ikonomovic MD, Styren SD, et al. Upregulation of choline acetyltransferase activity in hippocampus and frontal cortex of elderly subjects with mild cognitive impairment. Ann Neurol 2002;51:145-55.

45 Ikonomovic MD, Mufson EJ, Wuu J, et al. Cholinergic plasticity in hippocampus of individuals with mild cognitive impairment: correlation with Alzheimer's neuropathology. J Alzheimers Dis 2003;5:39-48.

46 Baskerville KA, Kent C, Personett D, et al. Aging elevates metabolic gene expression in brain cholinergic neurons. Neurobiol Aging 2008;29:1874-93.

47 Koch TR, Carney JA, Go VL, et al. Inhibitory neuropeptides and intrinsic inhibitory innervation of descending human colon. Dig Dis Sci 1991;36:712-8.

48 Yu Y, Daly DM, Adam IJ, et al. Interplay between mast cells, enterochromaffin cells, and sensory signaling in the aging human bowel. Neurogastroenterol Motil 2016:28:1465-79.

49 Moore H, Stuckman S, Sarter M, et al. Potassium, but not atropine-stimulated cortical acetylcholine efflux, is reduced in aged rats. Neurobio/ Aging 1996;17:565-71. 